\title{
16
}

\section{AFFORDABLE HOUSING DESIGN + A NEW URBAN ERA IN EUROPEAN CITIES}

\author{
Paul Karakusevic
}

\section{Introduction}

In cities across Europe, a new generation of practices is transforming affordable housing. Responding to ongoing demand and working with a set of newly energised public and community-focused clients, architects are once again playing a crucial role in addressing how homes are delivered at scale and advancing high standards of design ushering in a new urban era.

Across Europe, definitions of affordable and social housing vary from city to city. Each has its own municipal tradition, political landscape, architectural preferences and, alongside them, often complex funding cultures (Fezer et al., 2015). In London, there is a revival in direct publicled delivery; in Vienna and Berlin, cooperative and community projects are strongly supported; while in the cities of the Netherlands, a range of intermediate options is routinely pursued (Power, 1997). Each housing response and delivery methodology stems from its own context, but common to all is the idea that there are alternatives to a purely market-oriented system of provision, and that these are all crucial in delivering high quality, using resources sustainably and addressing equality of cities everywhere.

In 2015, Karakusevic Carson Architects was commissioned by the Royal Institute of British Architects (RIBA) to survey this emerging landscape and take stock of the range of different approaches being pursued by a range of practices across Europe. The result was a book Social Housing - Definitions and Design Exemplars published in 2017, which formed the basis of a touring design exhibition shown in London, New York and Calgary. Adopting a selection of criteria, with an emphasis upon exemplar processes with clients and communities, it features 24 case studies from 20 practices in seven countries. The international scope of the research highlights the variety of affordable and public housing projects being pursued and the range of innovative and sustainable design strategies that make them possible (Karakusevic and Batchelor, 2017). This chapter incorporates some of these examples and offers insights on the innovative ways in which affordable housing is being delivered in Rotterdam, Vienna and London. These projects pursue excellence through design, challenge how homes are created today and inform the design of affordable housing in future cities. Among the schemes discussed are public projects led by local authorities in London and collective schemes led by residents in Vienna and in Rotterdam. The projects of Karakusevic Carson Architects illustrate how design-led responses are 
enabling the implementation of new housing programmes and delivering affordable housing for communities in mixed-use, medium-density developments. These design and planning strategies are a vital part of ushering in a new era for affordable housing in cities.

\section{Renovation Strategies}

In the years following the Second World War, many of Europe's cities were left in a state of ruin and nearly all pursued programmes of reconstruction, with new housing embracing principles of modernist design and concrete construction. In the 1930s, pioneering projects in France and Germany did much to establish an appetite for a bold new architectural approach, and the outcome across the continent were ambitious variations on the tower or slab block in the urban landscape. While there are many celebrated and iconic examples of this approach, there are many more that have suffered badly in structural terms as the buildings reached the end of their life cycle. In some cases, housing became socially obsolete in the types of homes provided due to its inability to respond to changing demographics. Lack of integration in the urban landscape reinforced patterns of social and spatial segregation. Across many cities, the fabric of large postwar estates proved difficult to maintain, pushing municipal budgets amplified by economic change to the limits and leading to neglect and decline in the 1980s. Addressing the physical legacy of this period is one of the unifying architectural themes of European affordable housing today.

\section{Knikflats, Oommord, Rotterdam, The Netherlands BIQ / Hans van der Heijden}

In Rotterdam in the Netherlands, one district created in the post-war period is that of Ommoord on the northern outskirts of the city. Designed by Bauhaus urban planner Lotte Stam-Beese in 1968 , the ambitious project was built to house 35,000 people at a variety of scales and densities, with the largest type of housing including 15 eight-storey L-shaped blocks in a wideopen landscaped setting. The denser part of the district was constructed as a series of highrise slab block to accommodate a typically low-income community. BIQ's scheme dealt with four of the eight-storey blocks, which required renovation and updating. The estate's size means that any intervention in an individual block is also a strategic response to the whole, so the architect became a strategic member of the estate management team (van Der Heijden and Wessels, 2013).

The Knikflats project by BIQ / Hans van der Heijden was initiated in 2006 (Figure 16.1). The architect became part of the estate management team and worked closely with residents and client Woonbron Prins Alexander - one of around 425 registered housing associations who manage the bulk of the affordable housing stock in the Netherlands. In reconsidering the estate's future, demolition was not considered an option, partly due to the fact that many of the problems which have arisen over time could be traced back to the design of the communal access system and layout. In each of the huge concrete buildings, the 176 dwellings shared just two lifts and one entrance, putting the spaces under intense pressure. Residents had over half a century appropriated the neighbourhood as best they could, but the estate's abstract design made meaningful interaction between the buildings and the public spaces alongside them very challenging.

Two of the buildings were redeveloped as accommodation for the elderly people with the addition of a medical centre at the ground floor. In others, new homes were added to the bases of the blocks, purposefully expanding the original envelopes to create new inhabitable space 


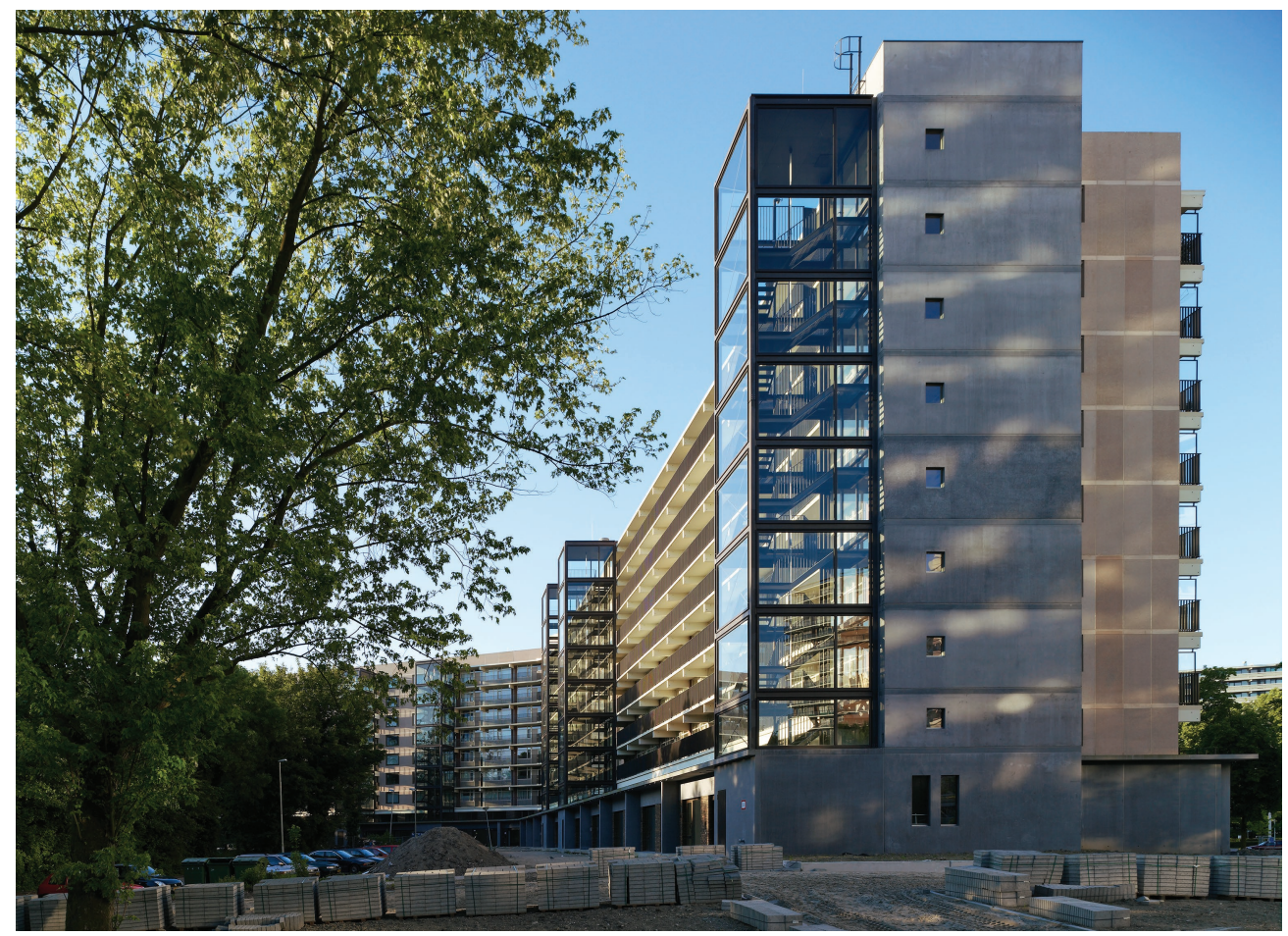

FIGURE 16.1 Architectural Intervention to the Blocks.

Source: Hans van der Heijden by Stefan Muller.

and employing earth red bricks to create warmth and texture in contrast to hard concrete above (Karakusevic and Batchelor, 2017). Two further blocks were redeveloped within the socalled 'customer choice' concept, a Dutch scheme similar to that of the 'Right to Buy' in the United Kingdom, but with tighter controls on occupation and sale. This means that the socioeconomic diversity of the residents will be greater, along with the existing ethnic diversity among the occupants across the blocks. BIQ's intervention is the result of a ten-year process to implement careful organisational changes to the blocks, avoiding unnecessary cosmetic changes in favour of meaningful, long-term alterations to adapt the blocks to a contemporary way of living.

\section{Kings Crescent Estate, London, Karakusevic Carson Architects}

In London, the Kings Crescent Estate renovation, led by Karakusevic Carson Architects in collaboration with Henley Halebrown for Hackney Council, similarly adopts a strategic approach to the reinvention of a post-war estate with a master plan providing $750+$ mixed-tenure homes with circa 500 new dwellings created alongside the retention and refurbishment of 175 existing homes (see Figure 16.2). Common to much comprehensive inner-city redevelopment across the United Kingdom, the 1970s era estate had suffered as a result of its disconnect from the wider historic neighbourhood, with a set of defensive linear blocks severing connections and the creation of a closed-off network of mono-cultural buildings and spaces within.

Started in 2012, our approach includes the intensive refurbishment of retained homes, residential infill of garage spaces and the introduction of new homes at its heart. Responding to the geometry of older blocks, new buildings work to form a series of rectilinear courtyards either 

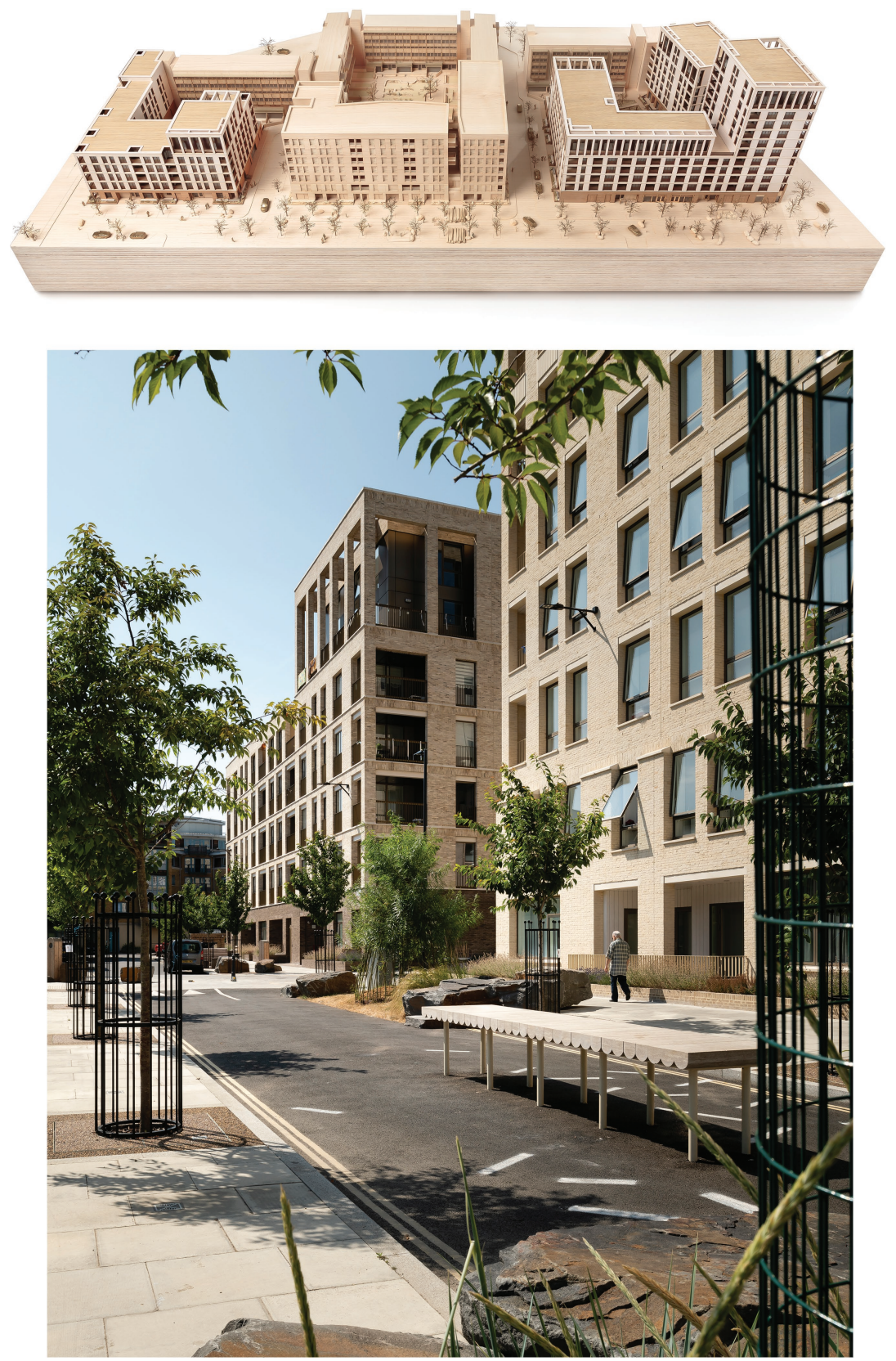

FIGURE 16.2 Kings Crescent Estate Model and Street View.

Source: Karakusevic Carson Architects, street view by Jim Stephenson.

side of a broad and open central street, with new workspace, community and retail uses introducing new life and activity. Completed in 2017, the first new buildings take their form from London's traditional urban 'mansion block' typologies and anchor the estate within the area with materials that complement the grain of nearby Victorian villas and terraces. Phases three and four received planning approval in 2019 and will be completed in 2023. 
At Kings Crescent, one of the greatest challenges faced by our studio was how to engage with a community left frustrated after 18 years of false starts. In 2001, approximately half of the estate had been demolished leaving a large hoarded-off wasteland of rubble. Later attempts to redevelop the area in 2007 and 2011 had both failed. Through regular steering group meetings and consultation events, residents were involved from the start on everything, from developing a site-wide strategy and the planning of new streets, right through to the internal specification of materials and the details of new homes. The role of people in the successful development of new affordable and public housing is crucial for cities everywhere. Consultation and engagement have been the core part of London's development process for many years, but there have been notable instances where processes have lacked sincerity and outcomes have not reflected local need in terms of the type of housing delivered. To promote a new level of transparency in the city, the Greater London Authority has introduced compulsory ballots with residents on grant-funded projects to ensure consultation when demolition of existing affordable housing is proposed. Introduced in 2016, it seeks to set a new benchmark for how engagement, participation and co-design processes work.

\section{New Processes with Residents}

\section{Wohnprojekt Wien, Vienna, Austria, by Einszueins}

Vienna has a long history of government-driven innovation in social housing provision as part of its strong tradition of welfare provision. Even today, Austria's biggest landlord remains the City of Vienna, which owns around 220,000 rental apartments, while 60\% of all Vienna households live in subsidised apartments. Throughout its post-war history, Austria has been particularly resistant to market forces, resulting in a stable housing market. Housing co-operatives form part of this history and the Einszueins' project in Vienna continue these themes in a contemporary context.

Located in the newly master planned neighbourhood of Nordbahnhofgelände, an area which for many years was the site of a railway freight yard, the 'Wohnprojekt Wien' by architects Einszueins follows in the new tradition of Vienna development. In this process, the city authorities purchase land, determine a new layout for the area and then tender out plots for development according to a sustainability framework. Plots are then sold to qualifying developers on the merits of the design proposals who receive subsidies to offset the development costs. Einszueins worked closely with the 'Wohnprojekt Wien' housing group to create 39 co-housing units which accommodate a wide mix of generations, languages and cultures including 67 adults and 25 children in a single building (Figure 16.3). The project is funded through a complex system of membership and 'asset pooling' which aims to keep the cost of housing permanently low. This model requires residents to commit to long-term investment and to engage proactively in the financial management of the building, as well as to maintain a $10 \%$ liquidity fund for maintenance of the building. This comparatively large co-housing organisation has an advantage of being able to retain a funding structure which smaller groups do not always have the capacity to pursue (Karakusevic and Batchelor, 2017).

The main emphasis of the project is the will of a self-organised community with the common aim to live together in the city in a sustainable, collaborative and open-minded way. The group describes itself as 'sociocratically organised', meaning that decisions are not based on a vote system but on the entire group openly discussing issues until a unanimous verdict is reached. This attitude is mirrored by that of the architects' proposals to maintain a level of simplicity in the structure to allow for user specification. Unit sizes range from $35 \mathrm{~m}^{2}$ studios 


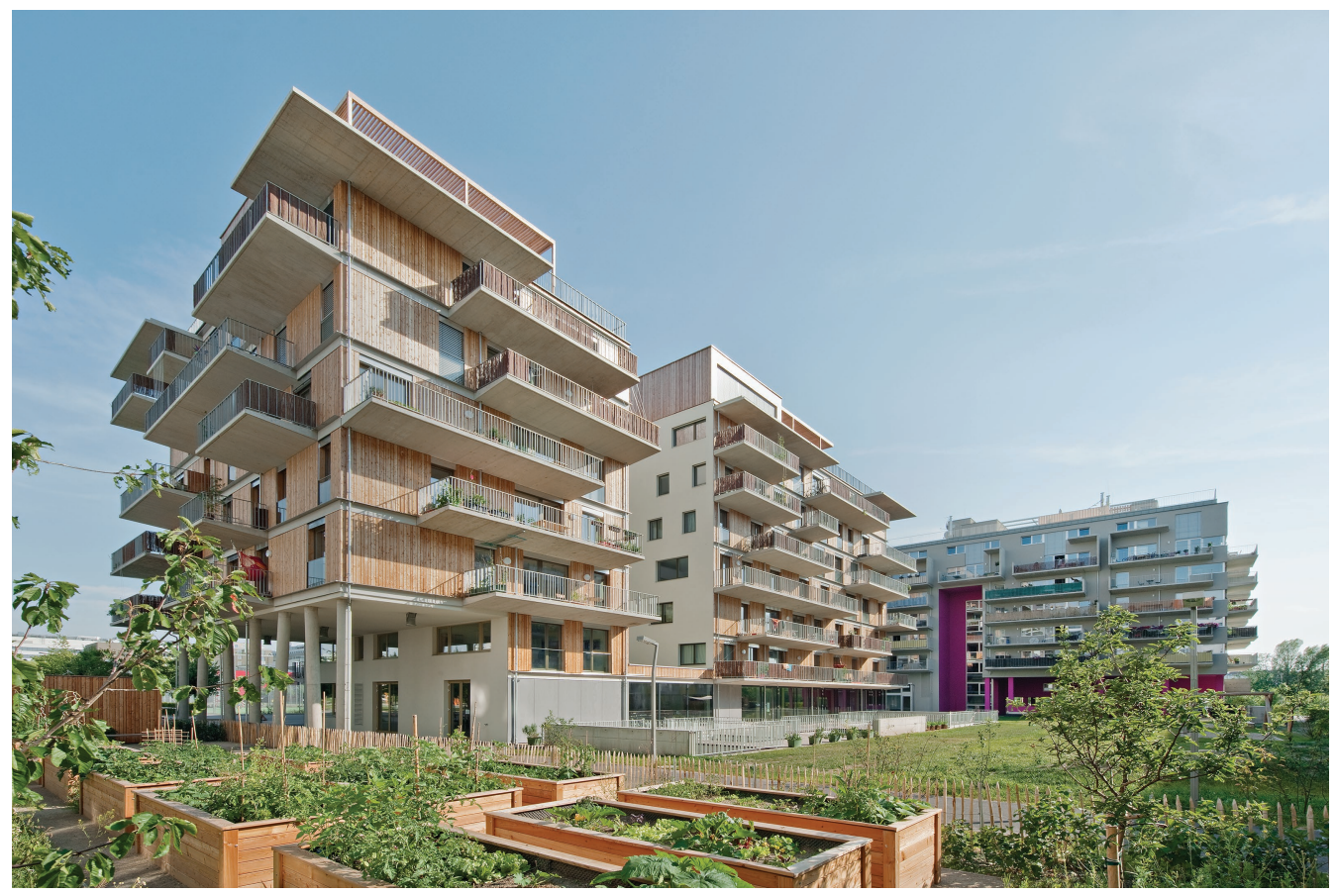

FIGURE 16.3 Wohnprojekt Wien Co-Housing.

Source: Einszueins by Hertha Hurnaus.

to $150 \mathrm{~m}^{2}$ shared apartments. Generous community and commercial spaces are managed by residents, which allows facilities such as a bike repair workshop and communal kitchens to create a lively and activated ground floor. Electric vehicles are used for residents to share trips, a weekly market is organised on the forecourt and vegetable gardens form part of the communal property.

The design strategy was initiated from the outset as a participatory process for the planning of the communal spaces and individual apartment units. This continued with the car sharing, a communal garden for the neighbourhood and ends with the common ownership of the building, resulting in active participation during all stages of the project's development. One of the fundamental aims of the project was to achieve a high level of individualisation inside the building envelope and to express this in terms of architectural design. For example, the void which runs alongside the main staircase facilitates spontaneous communication between residents, while the individual apartment units can act as spaces for retreat.

Some of the common spaces are located on the top floor, including a sauna, library and guest rooms, whereas on the lower floors, there is a communal kitchen, workshops and event rooms including a playroom for children and adults (Figure 16.4). The community also contributes to a fund, which allows two housing units to be used to accommodate people particularly in need of social care in the local community. The ground-floor commercial space is occupied by a small grocery store, which provides locally sourced produce to the community as well as hosting weekly performances and exhibitions. The notion of sustainability within the built environment is one which is often misused as a term for a developer's sales pitch or merely a blanket requirement placed on all new developments. However, in this model of co-housing, the term signifies a different meaning, specifically as a deliberate choice to live in a restrained and cooperative way. 


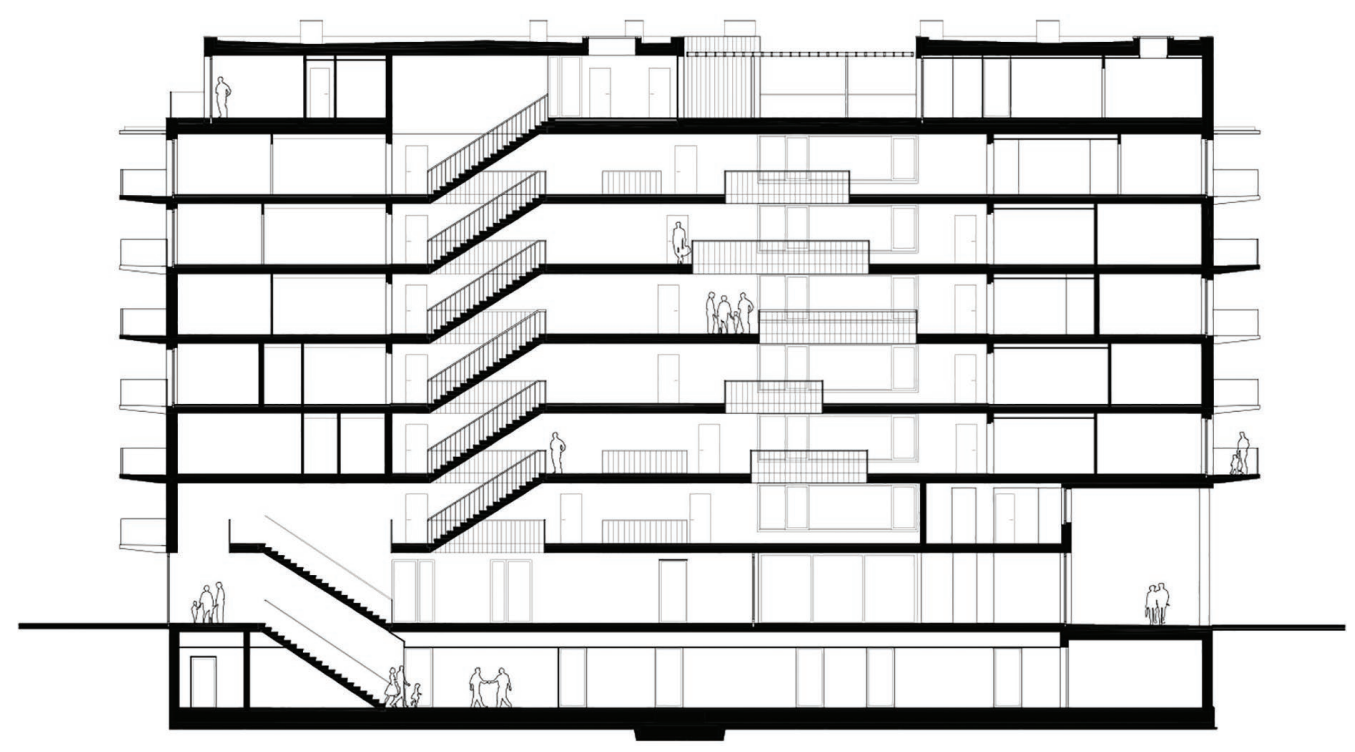

FIGURE 16.4 Wohnprojekt Wien Co-Housing-Common Spaces.

Source: Einszueins.

\section{Council Housing Reinvented}

In London, the re-establishment of a strong new public culture has been the key story of the past 20 years. At the end of the 19th century, London pioneered public housing and new dwelling standards. However, as funding was drastically cut in the 1980s, the abilities of local authorities or councils to plan their own affordable housing with any autonomy were curtailed. Shifting to a market-oriented system, the UK's urban public housing estates became neglected, with land sold off for redevelopment by the market, with very few terms and conditions attached about what types of dwellings should follow. In recent years, as a result of legislation allowing local government to lead council housing projects and borrow money, more new public projects are emerging that are setting new standards. In London, direct delivery of public housing is devolved to 32 Boroughs or municipalities. These local authorities or councils have their own housing portfolios, their own tenants and their own holdings, which they can put to use directly to create the type of housing and sustainable mixed urban neighbourhoods they want to see.

Located in the east of the city, The London Borough of Hackney was among the first to embrace a new housing programme of scale in 2008. Adopting a range of strategies including stock refurbishment, strategic infill on small sites as well as large housing estate redevelopment, the borough today uses its own land to reverse years of underinvestment. It has developed a new ambition for design within an expanded housing team, a process supported by London's upper tier of government, the Greater London Authority, through planning, training and enabling of affordable housing through provision of funds and subsidies.

\section{Colville Estate, London, United Kingdom, by Karakusevic Carson Architects}

One of the earliest and largest projects taken on by the council is the Colville Estate by Karakusevic Carson Architects. Adopted in 2012, the master plan for a worn-out 1950s estate consists of 


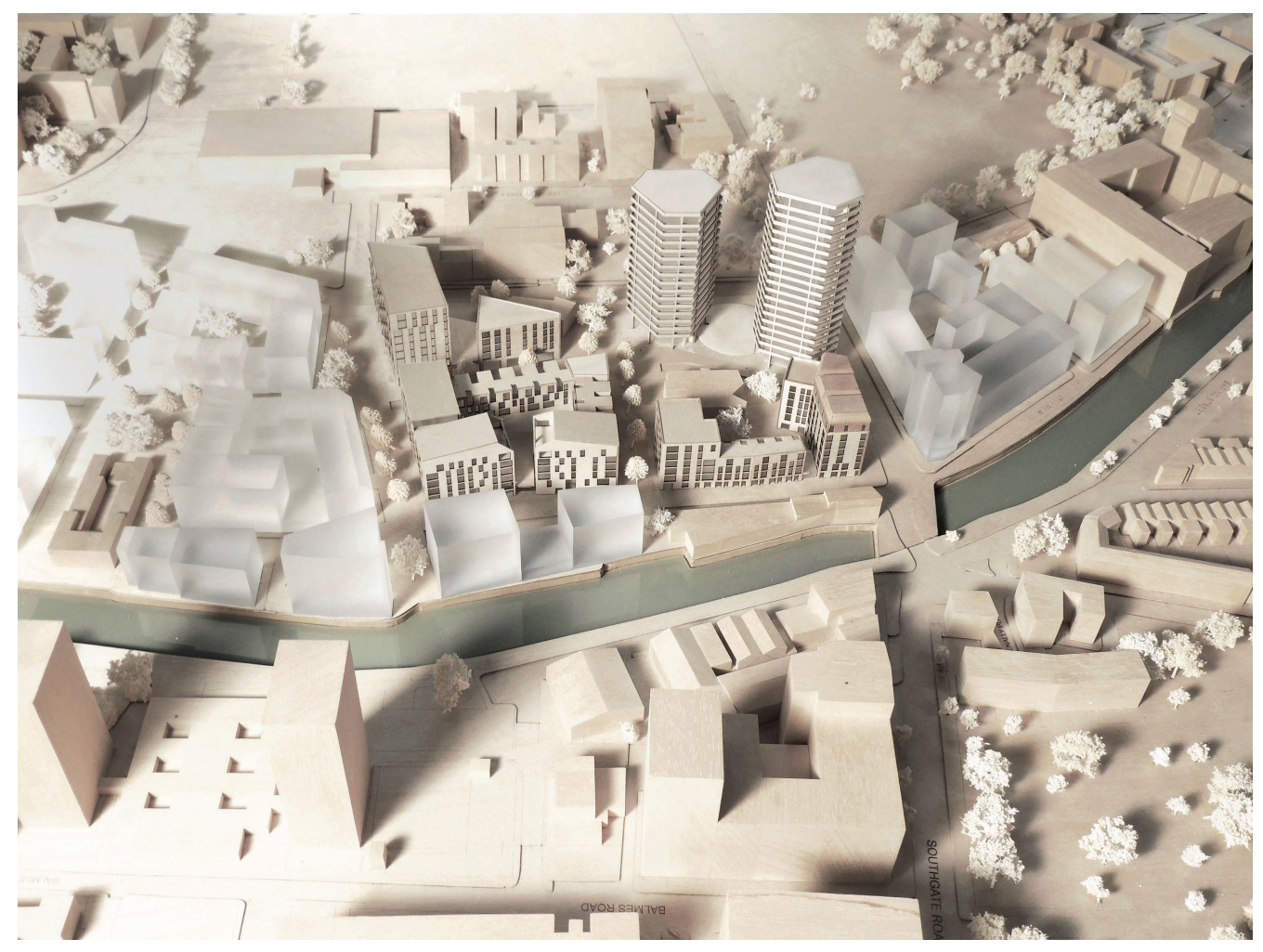

FIGURE 16.5 Colville Estate Master Plan Model.

Source: Karakusevic Carson Architects.

eight phases that will create a new neighbourhood of 925 homes with new amenities set amidst a network of humanely scaled public spaces and streets (Figure 16.5). As part of the design, we worked closely with an active and articulate community to realise a shared vision for comprehensive redevelopment and a totally reconceived piece of the city. The old estate consisted of 438 homes organised in rows of linear blocks typical of the post-war period, with inwardlooking service-dominated streets and courtyards, car parks and inaccessible or unused green spaces, which had little relationship with the wider area. Embracing the wishes of the existing community to live in low- to medium-rise housing, our approach creates a new townscape with a range of building types containing a mix of public, affordable and market sale homes and new amenities set amidst a network of accessible streets and humanely scaled public spaces.

Phase one was completed early in the programme in 2011 and enabled the process of rehousing existing residents. Phase two (Figure 16.6) was completed in 2017, and at its heart is a courtyard block with terraced and apartment buildings which were inspired by nearby historic forms that coalesce around a generous communal space at its core. Behind its various street facades are a series of interlocking and stacked homes that enables a wide variety of accommodation types and helps achieve a high density of homes. Brick colours and the textures of openings and balconies were chosen with the community and are used to create architectural order, but also vibrancy with recessed private terraces at roof level breaking the roofline line at regular intervals to create further character and generating exceptional living spaces.

Phase three (Figure 16.6) was completed in 2017 and includes Hoxton Press, two taller buildings designed in collaboration with David Chipperfield and taken forward for market 

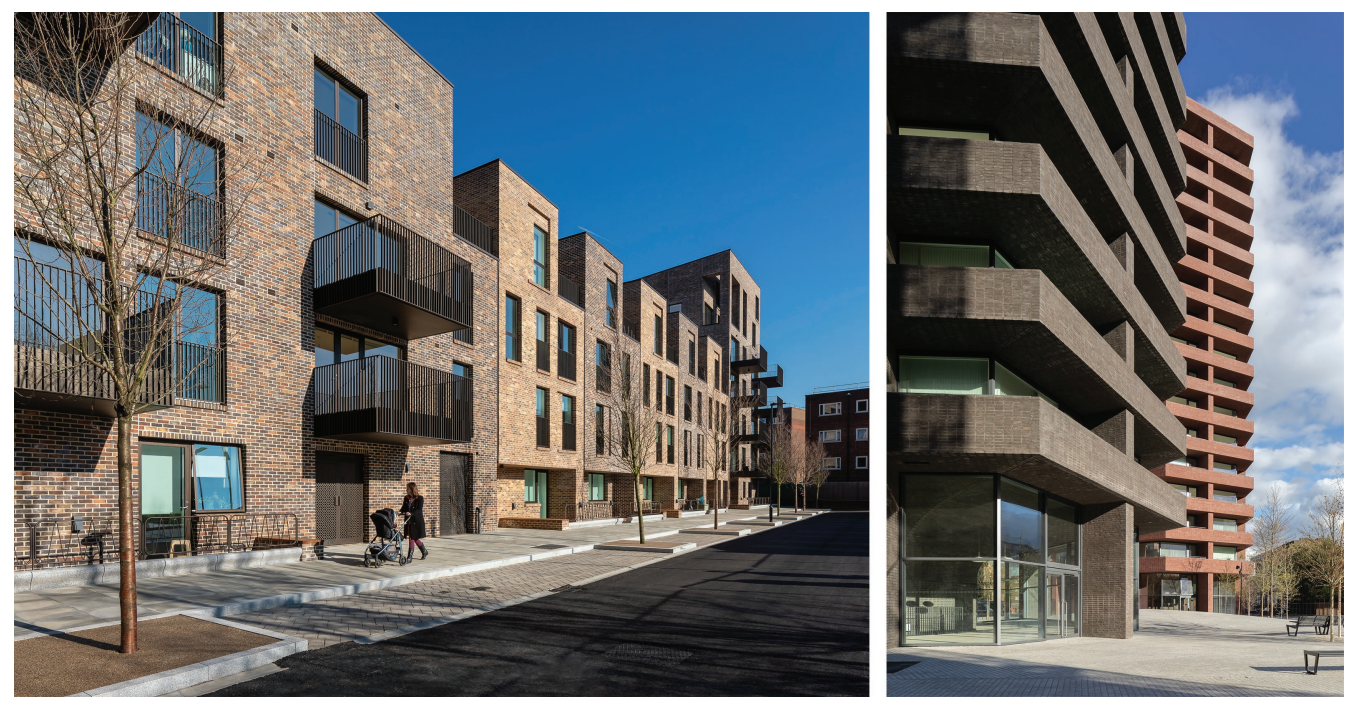

FIGURE 16.6 Colville Estate Developments in Phases Two and Three.

Source: Karakusevic Carson Architects by Peter Landers.

sale by a commercial developer to provide extensive cross-subsidy for affordable homes in the scheme. To ensure the architectural vision created for these elements was seen through, the developer was selected by the council after detailed planning with full design intent drawings and specifications had been achieved.

\section{Dujardin Mews, London, United Kingdom, by Karakusevic Carson Architects}

In Enfield, North London, we worked in a similar way to help the council realise Dujardin Mews, the first housing delivered directly by the borough in nearly four decades. Completed in 2017, the 38-home project forms the first phase of the Ponders End district rebuilding programme tasked to provide replacement homes for the neighbouring Alma Estate. Designed in collaboration with Maccreanor Lavington Architects, the project makes use of a narrow 0.70 hectare site that was formerly part of a nearby gas works (petroleum facility/station). This remediated land, next to the Oasis Academy School and a wider two-storey suburban neighbourhood, is now home to a new street of high-quality housing arranged in two terraces, establishing permeability through the site and important pedestrian connections between north and south. The development is a mix of 1-, 2-, 3- and 4-bedroom homes including dual aspect dwellings, with entrance doors facing the street to encourage activity, natural surveillance and create opportunities for neighbours to meet. The scale and massing of the street reflects the urban grain of the surrounding area to create a domestic and intimate character (Figure 16.7).

The eastern terrace comprises predominantly three-storey family homes, with an apartment building to the south. Houses are orientated west to the street, with sheltered first-floor terraces facing to the south, creating a layout where no habitable rooms overlook the neighbouring school. The design of the townhouses featuring pitched and mono-pitched roofs creates an articulated and varied street profile, which allows daylight to flood the street. The west terrace consists mainly of two-storey houses, with three-storey homes to the north, creating a mix of family-sized houses - maisonettes and apartments - in addition to hidden courtyards oriented behind brick street facades (Figure 16.8). 


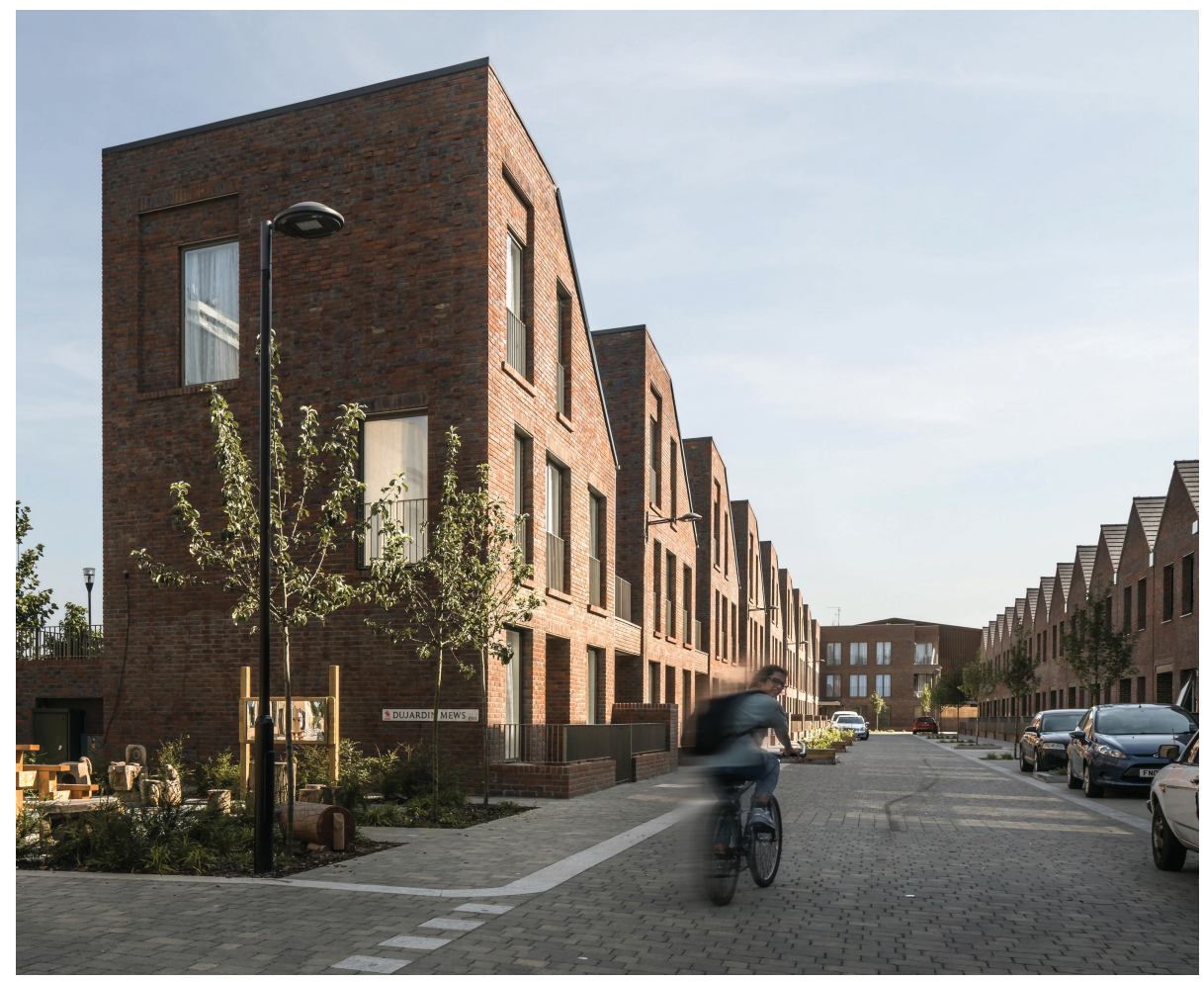

FIGURE 16.7 Council Housing Dujardin Mews - Street Profile.

Source: Karakusevic Carson Architects.
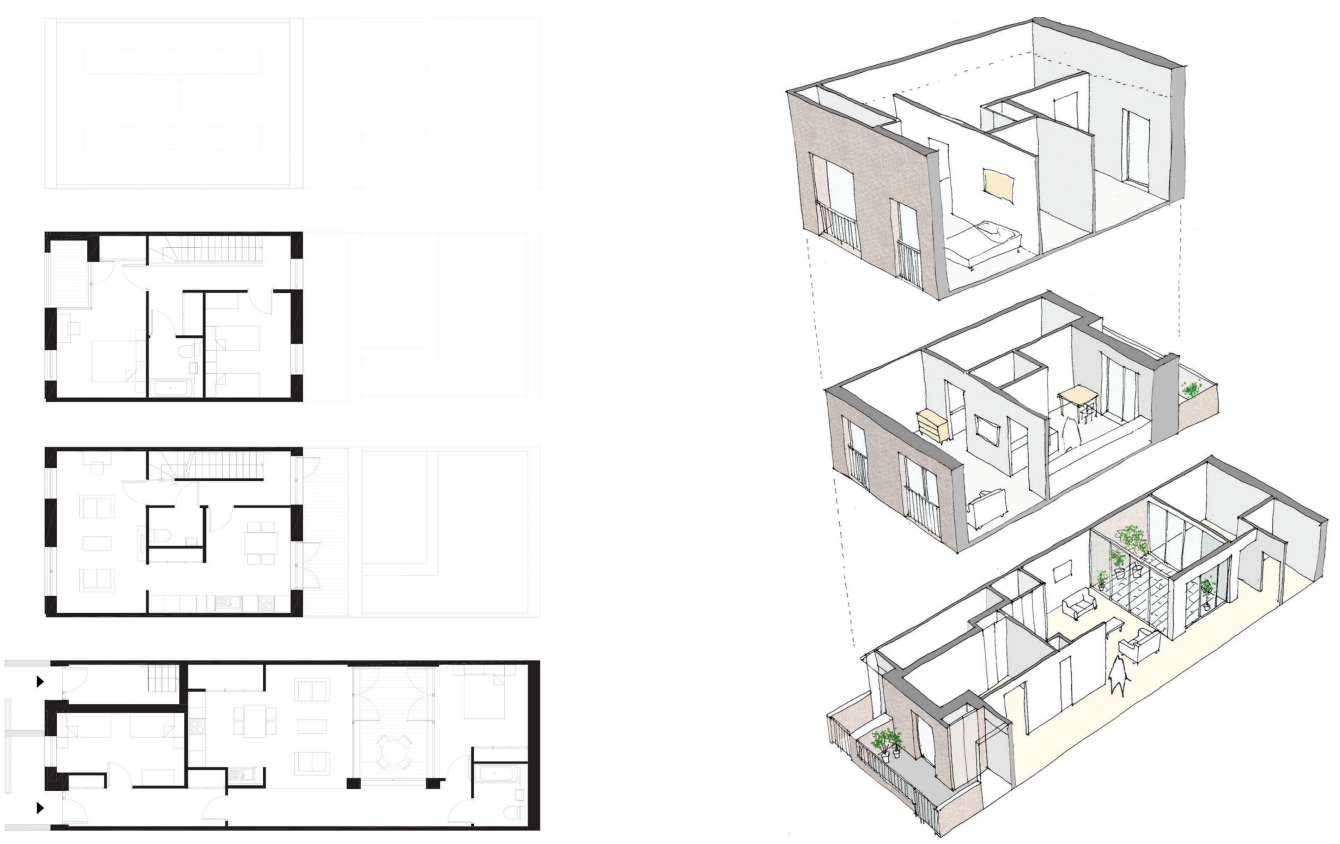

FIGURE 16.8 Council Housing Dujardin Mews - The Scheme.

Source: Karakusevic Carson Architects. 
Internal layouts for all homes exceed the London Housing Design Guide with generous spaces, substantial floor-to-ceiling heights, natural light and ventilation. The use of highquality materials and detailing in the form of textured brickwork, combined with pearl composite windows and matching metalwork, creates a sophisticated palette, which draws inspiration from the typical London street. Articulated brickwork predominantly featured on homes on the western terrace is designed to create interest up-close (see Althorpe and Batchelor, 2019). The project also enhances wider neighbourhood connections, ensuring the new homes are rooted in the ecology of the area and are an active part of the urban whole. New public spaces create a landscaped route through the street and areas for social activities. Community amenity to the north of the site buffers the Academy School's car drop-off area and provides a new play area and seating for residents and a pedestrian entrance to the new street. The success of Dujardin Mews is unprecedented for a local authority-led public housing project and is the result of an ambitious and cohesive client and design team.

\section{Learning From European Affordable Housing Projects}

Cities are many years in the making. To address the dual challenges of housing affordability and sustainability in the 21st century, urban leaders and clients need to take a long-term view, and, as the examples from Europe illustrate, they need to be increasingly ambitious in their thinking. Uniting many of the innovative social and affordable housing projects is a revitalised and robust public sector. Cities need strong civic cultures and proactive leadership that can act with autonomy and who are enthusiastic about design quality and working with communities. This means understanding neighbourhoods and knowing what great housing looks like, new and historically. But it also means implementing rigorous procurement processes and holding design teams to account throughout the process of development to maintain design intent, build quality and uphold environmental standards. To support these outcomes, robust spatial frameworks and a nuanced view to development have strong roles to play.

In many cities, the public sector or municipal body owns and may acquire large volumes of land. Rather than selling it off, it can put this asset to use to develop housing not only for and by itself, but in partnership with others as part of progressive good growth strategies. The examples of Vienna and in London demonstrate how local government can embed criteria at master planning stages to blend strategies between new build, infill and refurbishment and to promote better mix and a broader range of urban design responses, tenures and typologies.

Over the past 15 years, the United Kingdom has absorbed many lessons, and a growing number of urban councils are embracing new approaches. Momentum is now building around direct delivery even in cities where there was historic reluctance to develop public housing and pioneer programmes. New York, Sydney and Melbourne are starting to consider such approaches to respond to a growing shortage of affordable housing. To ensure these become reality, housing professionals of all kinds will need to think differently about city making and embrace the full cannon of alternative methods to create truly affordable and sustainable cities that can thrive and belong to everyone. Notwithstanding immense diversity of design approaches to affordable housing across European cities today, a few key strategies remain important.

\section{Regionalism}

Housing in most European countries is a devolved issue and is able to work independently of central government. In the case of the United Kingdom, after years of a strongly centralised state in terms of policy, new housing teams operating within local governments today are 
devising their own plans and borrowing to create public housing, often in ways that have to circumnavigate central government policy. Affordable housing needs ambitious and proactive local government that can work closely with communities and with the knowledge of local need (Förster and Menking, 2017, 2019).

\section{Client}

Great housing design needs clients that are ambitious about quality. This means knowing what great housing looks like, new and historically, but also about implementing rigorous and open procurement processes and holding design teams and value engineers/surveyors to account throughout the process to maintain quality and design intent.

\section{Public Land}

In the UK and in many other European states, the public sector owns and may acquire large volumes of land (University of the West of England, 2019). Rather than selling it off, it can put this asset to use to develop housing not only for and by itself, but as part of a nuanced and wideranging planning strategy. In Vienna and now in London, local or city government can develop a master plan for a site and release land for sale to a range of developers on a conditional basis in order to get the tenure mix and design quality it wants.

\section{Funding}

Public housing needs direct funding to enable its development. Government grants and seed funding can work to prepare sites and guarantee additional borrowing to keep prices low and offset risk to local authorities. Small funding in these areas can yield long-term benefits (Kubey, 2018).

\section{Nuance}

Refurbishment of old housing estates and neighbourhoods must be responsive to need and what is desirable and achievable on site. One size does not fit all. Developments across Europe actively blend strategies on site with new build supporting infill and refurbishment (Boughton, 2018).

\section{Long Termism}

New housing rarely happens at speed. Projects across Europe have been years in the making and they are the result of long-held plans that embed long-term environmental + retrofit objectives, for example, Passivhaus and strategies of land assembly and phased development. A long-term project requires ring-fenced funding and political commitment so that communities are not blighted by stalled processes and disputes (Housing Europe, 2019).

\section{People}

In various parts of Europe, people-led housing is a strong part of delivery. Elsewhere, notably in the UK, co-design processes are taking forward schemes that have previously been resisted by communities. New affordable housing on public land requires an open and upfront dialogue with their future inhabitant and those in the neighbourhoods they adjoin (Swenarton, 2018). 


\section{References}

Althorpe, M. and A. Batchelor (2019). Revolutionary Low Rise - Informing London's Suburban Densification. http://karakusevic-carson.com/system/dragonfly/production/2019/10/28/8bt67uvljt_ Revolutionary_Low_Rise_PDF_071019.pdf, accessed October 5, 2019.

Boughton, J. (2018). Municipal Dreams: The Rise and Fall of Council Housing. London: Verso.

Fezer, J., C. Hiller, and N. Hirsch (2015). Housing after the Neoliberal Turn: International Case Studies. Berlin: Spector Books \& HKW.

Förster, W. and W. Menking (2017). The Vienna Model: Housing for the Twenty-First Century City. Berlin: Jovis.

Förster, W. and W. Menking (2019). The Vienna Model 2. Berlin: Jovis.

Housing Europe (2019). Website. www.housingeurope.eu/, accessed October 21, 2019.

Karakusevic, P. and A. Batchelor (2017). Social Housing: Definitions and Design Exemplars. Newcastle upon Tyne: RIBA Publishing.

Kubey, K. (2018). Housing as Intervention: Architecture towards Social Equity. West Sussex: John Wiley \& Sons Ltd.

Power, A. (1997). Estates on the Edge: Social Consequences of Mass Housing in Northern Europe. New York: St. Martin's Press.

Swenarton, M. (2018). Cook's Camden: The Making of Modern Housing. London: Lund Humphries.

University of the West of England (2019). History of Council Housing (UK). Bristol: University of the West of England. https://fet.uwe.ac.uk/conweb/house_ages/council_housing/print.htm, accessed October 6, 2019.

van Der Heijden, H., \& Wessels, R. (2013). Habitat: Biq bouwt de stad / biq Builds the City. In Woodman, E. (ed). Rotterdam: Nai Uitgevers Publishers: 4-8. 